\title{
Quantification of wear-time adherence of removable appliances in young orthodontic patients in relation to their BMI: a preliminary study
}

\author{
This article was published in the following Dove Press journal: \\ Patient Preference and Adherence \\ 17 November 2014 \\ Number of times this article has been viewed
}

\author{
Timm Cornelius Schott ${ }^{1}$ \\ Björn Ludwig',3 \\ 'Department of Orthodontics, \\ Eberhard Karls University, Tübingen, \\ Germany; ${ }^{2}$ Private practice, Traben- \\ Trarbach, Germany; ${ }^{3}$ Department of \\ Orthodontics University of Homburg/ \\ Saar, Germany
}

Purpose: The relationship between unhealthy body mass index (BMI) and adherence to orthodontic treatment with removable appliances has not previously been evaluated.

Objective: The aim of this study was to quantify the association between BMI and wear time of removable orthodontic appliances and to evaluate BMI changes during orthodontic treatment. Patients and methods: Fifty-three normal-weight and 39 overweight/obese children and adolescents (7-15 years old) undergoing orthodontic treatment with removable appliances were enrolled into the study. BMI categories were determined using standardized age-specific and sex-specific BMI criteria, using data measured at the beginning of therapy and once during orthodontic treatment. Wear times of removable appliances were measured at 15-minute intervals over a period of 5 months using implanted microelectronic sensors. Median wear-time values were used in the analysis with the Mann-Whitney $U$-test used to test statistical differences between groups.

Results: The median wear time of removable orthodontic appliances was 9.3 hours for normalweight patients and 9.2 hours for overweight/obese patients. No statistically significant $(P>0.05)$ or clinically relevant differences in usage or adherence were detected between normal-weight and overweight/obese patients. BMI did not influence wear time or behavior of removable orthodontic appliances by young patients. The majority of patients showed qualitative decreases in BMI during therapy.

Conclusion: The orthodontic treatment of young patients with removable devices does not require BMI-dependent changes in the treatment strategy. However, the use of removable appliances during meal times raises the possibility of reducing food intake, and in this way the orthodontist may have an active role to play in weight reduction.

Keywords: pediatrics, obesity, adherence, orthodontics, BMI

\section{Introduction}

The World Health Organization classifies childhood obesity as one of the most serious public health challenges of the 21 st century. ${ }^{1}$ Obese children are at risk of developing various diseases, ${ }^{2-7}$ including type 2 diabetes mellitus ${ }^{8}$ and cardiovascular and gastrointestinal disorders. ${ }^{9}$ In addition, obstructive sleep apnea syndrome, ${ }^{10,11}$ social exclusion, and depression are common in obese patients. ${ }^{12-14}$ From a dentist's perspective, obese children and adolescents appear to exhibit more carious lesions and cavities, ${ }^{15-20}$ although these findings are disputed..$^{21}$ Other studies in adolescents have shown associations between obesity and periodontal risk indicators that - in the long-term - may lead to oral morbidity. ${ }^{22,23}$
Correspondence: Timm Cornelius Schott Department of Orthodontics and Orofacial Orthopedics, University Hospital of Dentistry, Oral Medicine, and Maxillofacial Surgery, Eberhard Karls University, Tübingen, Osianderstr 2-8, 72076 Tuebingen, Germany

Tel +49 707। 2982 I 62

Fax +49 707I 65782

Email timm.schott@med.uni-tuebingen.de submit your manuscript | www.dovepress.com

Dovepress

http://dx.doi.org// 0.2147/PPA.S69586 
Recognizing that differences exist between obese and normal-weight orthodontic patients is gaining recognition as an important research theme. ${ }^{24}$ The influence of obesity on the treatment of orthodontic patients has not been well evaluated, and there is a pressing need for more research in this area as the number of obese patients requiring orthodontic treatment continues to grow. There are several reasons why orthodontic therapy might be affected by obesity: ${ }^{25}$ pubertal development is altered by the hormonal changes associated with obesity; and bone metabolism might differ in obese patients, leading to growth and developmental changes or tooth movement. In addition, there are recognized psychiatric and psychological issues associated with obesity in adolescence that can affect adherence to the therapy protocol.

An initial study that investigated the correlation between body mass index (BMI) and orthodontic treatment outcomes during treatment with multibracket appliances concluded that the group of children with higher BMIs did not cooperate as well as normal-weight peers; however, the treatment outcome was similar between the two groups. ${ }^{26}$ There is little evidence on whether adherence to treatment plans by obese patients fundamentally differs from normal-weight patients and, therefore, needs to be considered in their management.

The success of orthodontic treatment with removable devices is dependent on regular wearing of the device at the prescribed times, but accurately measuring adherence has, until recently, been a challenge. We therefore used temperature-sensitive microsensors (TheraMon ${ }^{\circledR}$ System; Handelsagentur Gschladt, Binderberg, Austria) incorporated into the removable appliances by polymerization to measure wear times of upper jaw and functional (jumping-the-bite) appliances in both normal-weight and overweight/obese patients over a period of several months.

The purpose of this study was to identify differences in usage behavior that would justify modifying treatment plans for different groups of patients. In addition, since the extent to which the BMI of young obese patients changes during the course of orthodontic treatment has not been studied, the BMI of patients was also qualitatively evaluated.

\section{Materials and methods}

\section{Subjects}

The study population consisted of patients who visited a private German orthodontic practice from December 2010-July 2012. The inclusion criteria were: aged from 7-15 years; not suffering from any previous illnesses; indication for orthodontic therapy with removable upper jaw active plates or functional (jumping-the-bite) appliances; and integration of an electronic microelectronic sensor into the orthodontist appliance. The recorded median wear times had to be more than 2 hours per day throughout the first 5 months of treatment as a minimum value for "adherence". All patients and guardians received detailed information about the purpose of the study and provided written informed consent prior to enrollment in the study. Permission was granted to use microelectronic, built-in sensors as part of the treatment, and the study was conducted in accordance with the ethical standards of the responsible institutional committee of the University of Tübingen, Germany (Registration number 339/2012B01).

\section{Measurements}

Body height (in meters) was measured to the nearest $0.1 \mathrm{~cm}$, without shoes, using a portable stadiometer with the head in the Frankfurt plane. The body weight (in kilograms) with light clothing was recorded to the nearest $0.1 \mathrm{~kg}$ on a calibrated digital scale during the appointment when the orthodontic appliance was fitted. BMI was calculated as

$$
\text { weight } / \text { (height } \times \text { height) in } \mathrm{kg} / \mathrm{m}^{2} \text {, }
$$

and individual BMI percentiles were derived according to age and sex. For descriptive purposes, children were categorized as being of normal weight, overweight, and obese at the start of treatment using cutoffs established by the Arbeitsgruppe Adipositas im Kindes - und Jugendalter for children and adolescents in Germany ${ }^{27}$ and according to the recommendations of the International Obesity Task Force ${ }^{28}$ (Tables 1 and 2). For patients aged 2-19 years, overweight was classified as BMI percentiles $\geq 90$ and $<97$, obese $\geq 97$ and $<99.5$, and severely obese as $\geq 99.5 .{ }^{27}$ The BMI standard deviation scores were calculated based on the LMS method. ${ }^{29}$ During the course of treatment, BMIs were determined again either in the first, second, or third year of therapy, and the period between the first and second measurement was calculated in months.

\section{Removable orthodontist appliances, recording of wear times, and wear-time adherence}

Forty-two patients were treated with removable upper jaw active plates (A) and 53 patients with jumping-the-bite appliances (B).

The commercially available microelectronic TheraMon ${ }^{\circledR}$ Sensor (Handelsagentur Gschladt) was fitted into the appliances, as previously described. ${ }^{30}$ The microsensors are designed to run over a period of over 700 days. Throughout the period of therapy, the sensors measured the intraoral temperature at 15 -minute intervals. Stored temperature values 
Table I Demographics and wear times of overweight (defined by BMI percentile 90-96) children and adolescents undergoing orthodontic therapy

\begin{tabular}{|c|c|c|c|c|c|c|}
\hline $\begin{array}{l}\text { Patient } \\
\text { number }\end{array}$ & Sex & $\begin{array}{l}\text { Age } \\
\text { in years }\end{array}$ & $\begin{array}{l}\text { BMI } \\
\text { percentile }\end{array}$ & SDS $_{\text {LMS }}$ & $\begin{array}{l}\text { Treatment } \\
\text { appliance type }\end{array}$ & $\begin{array}{l}\text { Daily wear } \\
\text { time in hours }\end{array}$ \\
\hline \multicolumn{7}{|c|}{ Overweight } \\
\hline 1 & $M$ & 10.6 & 90.3 & 1.30 & $A$ & 9.4 \\
\hline 2 & $M$ & 11.9 & 90.3 & 1.30 & B & II.I \\
\hline 3 & $M$ & 8.3 & 91 & 1.37 & $A$ & II.I \\
\hline 4 & $\mathrm{~F}$ & 10.9 & 92 & 1.39 & B & 2.1 \\
\hline 5 & $M$ & 12.1 & 91.9 & 1.40 & B & 9.0 \\
\hline 6 & $M$ & 15.7 & 91.9 & 1.40 & $A$ & 10.6 \\
\hline 7 & $M$ & 9.1 & 91.9 & 1.40 & $A$ & 8.8 \\
\hline 8 & $M$ & 8.8 & 94 & 1.48 & A & 11.5 \\
\hline 9 & $F$ & 15.3 & 95.3 & 1.50 & A & 2.5 \\
\hline 10 & $M$ & 8.10 & 93.3 & 1.50 & B & 9.1 \\
\hline II & $\mathrm{F}$ & 7.9 & 93.3 & 1.50 & $A$ & 9.6 \\
\hline 12 & $\mathrm{~F}$ & 9.8 & 93.3 & 1.50 & B & 8.4 \\
\hline 13 & $\mathrm{~F}$ & 10.5 & 93 & 1.50 & $A$ & 8.6 \\
\hline 14 & $\mathrm{~F}$ & 10.6 & 94 & 1.53 & A & 9.3 \\
\hline 15 & $M$ & 10.2 & 94 & 1.55 & $A$ & 13.5 \\
\hline 16 & $M$ & 8.6 & 94 & 1.58 & $A$ & 9.1 \\
\hline 17 & $\mathrm{~F}$ & 9.9 & 95 & 1.63 & $A$ & 9.2 \\
\hline 18 & $\mathrm{~F}$ & 8.9 & 95 & 1.66 & $B$ & 9.3 \\
\hline 19 & $\mathrm{~F}$ & 10.2 & 95 & 1.66 & B & 10.6 \\
\hline 20 & $\mathrm{~F}$ & 7.9 & 95.5 & 1.70 & $A$ & 13.3 \\
\hline \multirow[t]{2}{*}{21} & $M$ & $13.1 \mid$ & 96.4 & 1.80 & $A$ & 7.9 \\
\hline & & Mean 10.6 & & & & Median 9.3 \\
\hline
\end{tabular}

Note: Wear time was microelectronically documented during 5 months of treatment.

Abbreviations: BMI, body mass index; SDS, standard deviation score; M, male; A, upper jaw active plates; B, jumping-the-bite appliances; F, female.

Table 2 Demographics and wear times of obese (BMI percentile $97<99.5)$ and severely obese $(\geq 99.5)($ defined by BMI percentile) children and adolescents undergoing orthodontic therapy

\begin{tabular}{|c|c|c|c|c|c|c|}
\hline $\begin{array}{l}\text { Patient } \\
\text { number }\end{array}$ & Sex & $\begin{array}{l}\text { Age } \\
\text { in years }\end{array}$ & $\begin{array}{l}\text { BMI } \\
\text { percentile }\end{array}$ & $\mathbf{S D S}_{\text {LMS }}$ & $\begin{array}{l}\text { Treatment } \\
\text { appliance type }\end{array}$ & $\begin{array}{l}\text { Daily wear } \\
\text { time in hours }\end{array}$ \\
\hline \multicolumn{7}{|l|}{ Obese } \\
\hline 22 & M & 9.4 & 97 & 1.82 & A & 12.0 \\
\hline 23 & $\mathrm{~F}$ & 12.7 & 97 & 1.84 & B & 7.7 \\
\hline 24 & $\mathrm{~F}$ & 11.4 & 97 & 1.89 & B & 10.3 \\
\hline 25 & $M$ & 13.8 & 97 & 1.91 & B & 7.7 \\
\hline 26 & $\mathrm{~F}$ & 8.1 & 97 & 1.96 & $A$ & 6.4 \\
\hline 27 & M & 11.9 & 97.7 & 2.00 & B & 9.5 \\
\hline 28 & M & 8.0 & 97.7 & 2.00 & B & 10.1 \\
\hline 29 & $\mathrm{~F}$ & 15.7 & 98 & 2.02 & B & 6.0 \\
\hline 30 & M & 14.4 & 98 & 2.07 & B & 8.0 \\
\hline 31 & $M$ & 12.6 & 98.9 & 2.30 & B & 8.6 \\
\hline \multirow[t]{2}{*}{32} & M & 11.3 & 99 & 2.19 & B & 5.6 \\
\hline & & Mean 11.9 & & & & Median 8.0 \\
\hline \multicolumn{7}{|c|}{ Severely obese } \\
\hline 33 & M & 11.7 & $\geq 99.5$ & 2.38 & B & 8.4 \\
\hline 34 & M & 13.9 & $\geq 99.5$ & 2.47 & A & 6.0 \\
\hline 35 & M & 15.1 & $\geq 99.5$ & 2.67 & B & 7.8 \\
\hline 36 & $M$ & 15.9 & $\geq 99.5$ & 2.75 & B & 7.5 \\
\hline 37 & $\mathrm{~F}$ & 11.2 & $\geq 99.5$ & 2.90 & B & 9.2 \\
\hline 38 & M & 8.4 & $\geq 99.5$ & 2.94 & $A$ & 11.3 \\
\hline \multirow[t]{2}{*}{39} & M & 10.11 & $\geq 99.5$ & 2.90 & B & 14.6 \\
\hline & & Mean 12.9 & & & & Median 8.4 \\
\hline
\end{tabular}

Note: Wear time was microelectronically documented during 5 months of treatment.

Abbreviations: BMI, body mass index; SDS, standard deviation score; M, male; A, removable orthodontic plates; F, female; B, functional appliances. 
were transferred electronically to the analysis computer and software and converted into wear-time or nonweartime parameters (TheraMon ${ }^{\circledR}$ software, version 2.1.0.13; Handelsagentur Gschladt). ${ }^{31,32}$ At every check-up appointment, these data were collected from the device and displayed as wear-time graphs for easy visualization and analysis of the prescribed wear time, the median wear time over the evaluation period, and the daily wear time.

Several recent studies have shown that the majority of young or adolescent patients do not adhere to the prescribed standard wear times of 12-15 hours/day. However, there is empirical evidence to suggest that treatment with removable devices worn for about 9 hours/day is likely to be successful and practical, with several reports of achievable median wear times of $8-9$ hours/day (9.0 hours/day, ${ }^{33} 9.0$ hours/day, ${ }^{34}$ 8.3 hours/day, ${ }^{35}$ and 8.1 hours $/$ day $^{36}$ ). A median wear time of 9 hours/day is known to be influenced by sex, age, and place of treatment, but not by the type of device. ${ }^{33}$ Wear times of $<9$ hours/day are likely to risk treatment efficacy, and successful tooth realignment is thought to occur when pressures act for 6 or more hours a day; ${ }^{37}$ patients were therefore defined as "at risk" when they had median wear times of $<7$ hours/day.

\section{Statistical methods}

A sample size calculation was performed using the R Project for Statistical Software package, version 2.15.0 (R Foundation for Statistical Computing, Vienna, Austria) (www.r-project.org). For a power of $80 \%$, significance level of 0.05 , and to detect clinically meaningful differences in wear time (which means 8 hours or the prescribed time of 11 hours), 55 patients were enrolled in the normal-weight study group and 39 in the overweight/obese study group (BMI percentile $\geq 90$ ).

All other data were analyzed using SPSS software (IBM SPSS Statistics, release 20.0; IBM Corporation, Armonk, NY, USA). The analyzed variables were median wear times for each patient. The distribution of variables was examined with histograms and using the Shapiro-Wilk test. The data were not normally distributed; we therefore used the Mann-Whitney $U$-test to compare wear times between normal-weight and overweight/obese patient groups. The level of significance was set at 0.05 .

\section{Results}

\section{Sample description}

Twenty-three percent of a total of 167 patients assessed over the treatment period were overweight/obese. Due to the sample size calculation, the wear times of the first 55 patients with normal weight and all 40 overweight/obese patients were considered. Two normal-weight patients and one obese patient did not fulfill the inclusion criteria, as their treatment was cancelled due to lack of adherence. Fifty-three normalweight patients (32 males and 21 females) and 39 overweight/ obese patients (24 males and 15 females) were included. On average, normal-weight patients had BMI percentiles of 55.1 and were from 7.9-15.9 years old (mean: 11.2 years [standard deviation $\{\mathrm{SD}\}: 2.2$ years]). Overweight/obese patients were on average 11.2 years (SD: 2.6 years) old. The distribution of the devices in the normal-weight group was: $\operatorname{appliance}(A)$, number $(n)=24$; and appliance $(B), n=32$. The distribution of the devices in the overweight/obese group is shown in Tables 1 and 2.

\section{Wear-time measurements}

The recording of wear times took place over a 5-month treatment period. Normal-weight patients wore the appliances from 2.6-17.0 hours per day, representing a median daily wear time of 9.3 hours. Overweight/obese patients (Tables 1 and 2), which included 21 overweight, eleven obese, and seven severely obese patients, wore the appliances from 2.1-14.6 hours per day, representing a median daily wear time of 9.2 hours; this was not significantly different $(P>0.05)$. The median daily wear time of $\sim 9$ hours was similar to that previously reported, ${ }^{38}$ and as described previously. Nine out of $53(17.0 \%)$ normal-weight patients and 12 out of 39 (30.7\%) overweight/obese patients wore their appliances for a median of over 10 hours a day.

The median wear time of overweight patients (Table 1) was 9.3 hours -8.0 hours in obese patients, and 8.4 hours in severely obese patients. Two patients in the overweight group, three in the obese group, and one in the severely obese group were "at risk" candidates with daily wear times from 2.1-6.4 hours/day. There were no clinically or significantly relevant differences $(P>0.05)$ in the overall treatment period and median daily wear times between groups. Median wear times were lower if patients did not wear their appliances at all on some days. However, wear times of over 10 hours can occur from regular, but variable, daily usage. Previous detailed analysis using the TheraMon ${ }^{\circledR}$ software has shown that appliances are mainly worn at night and only sporadically during the day. ${ }^{39}$

A second BMI evaluation was carried out 6-36 months after the initiation of therapy, which revealed a reduction in BMI in the majority of overweight/obese patients. Only five of 39 patients had a static or increased BMI over the course 
of treatment (Figures 1 and 2); these BMI changes were not associated with wear time. Comparable reductions in BMI were observed in some patients after 1 year and in others only after 3 years. In 17 of 21 overweight patients (BMI percentile: 90-96) (Figure 1), significantly lower BMI values in the 42-93 range were measured during the second evaluation, with two patients even achieving a BMI percentile $\leq 50$ during the treatment period after 17 months and 35 months, respectively. A slight increase in BMI was detected in only four overweight patients. During therapy, nine patients were reclassified from obese to overweight. Two patients had stable or slightly increased BMI values. In two out of seven severely obese (BMI percentile $\geq 99.5$ ) patients, the initial values dropped to 86 in the second measurement - the first after 6 months and the second after 30 months.

\section{Discussion}

In this paper, we evaluated whether overweight or obese patients exhibit differences in wear-time adherence and behavior to normal-weight patients wearing removable orthodontic appliances using sophisticated and objective electronic wear-time monitoring.

The microelectronically measured median wear times of obese and nonobese young orthodontic patients were nearly identical. Several previously identified parameters, such as age and sex, are likely to influence the wear-time adherence of both weight groups in a comparable manner. ${ }^{33}$ Of clinical relevance for treatment with removable devices, the majority of obese patients achieve the median wear time and adherence levels and, therefore, do not need to be treated differently to nonobese patients.

Our study not only quantifies the median wear time, but also the associated wear behavior. The majority of these young patients showed discontinuous wear behavior, ${ }^{39}$ the typical pattern being to not wear the device on some days and then trying to compensate for this by wearing the device more on other days. Overall, this discontinuous wear behavior resulted in a low median wear time, and remotivating the patient during consultations can persistently reduce the number of zero wear-time days over the course of subsequent therapy.

It is difficult to predict how an individual appliance transfers forces to the dental alveolar complex and, therefore, exactly how wear times and behavior relate to treatment progress. However, the orthodontist can assess treatment progress at check-up appointments and assess prognoses for patients with removal appliances based on the evaluated adherence. Based on our practical experience, patients who

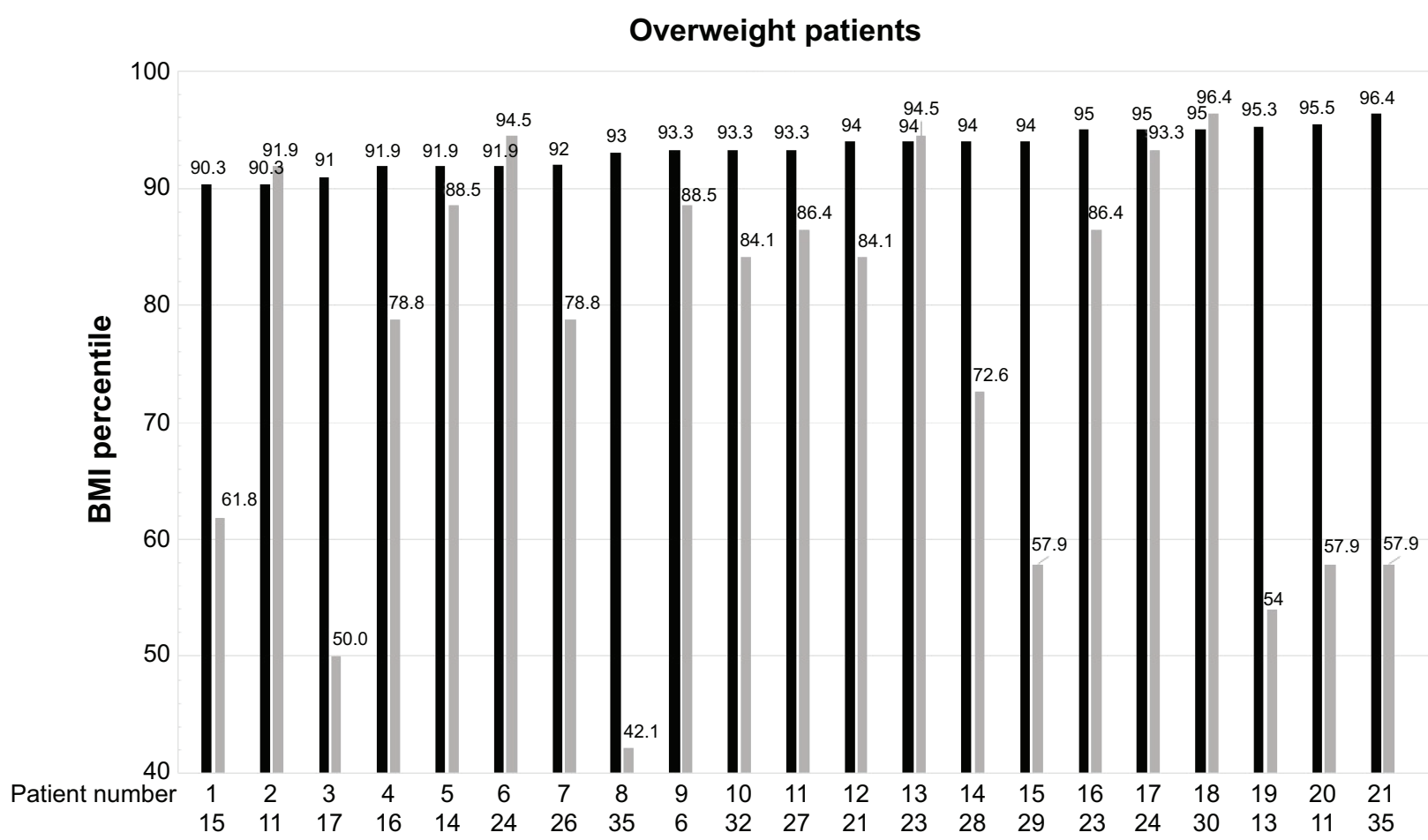

Figure I BMls of $2 \mathrm{I}$ overweight patients (patient numbers I-2I) at the beginning of treatment and at the second measurement, 6-35 months later.

Notes: Black column: beginning of treatment; gray column: second measurement (6-35 months later). Months between first and second BMI evaluations are given in the second line.

Abbreviation: BMI, body mass index. 


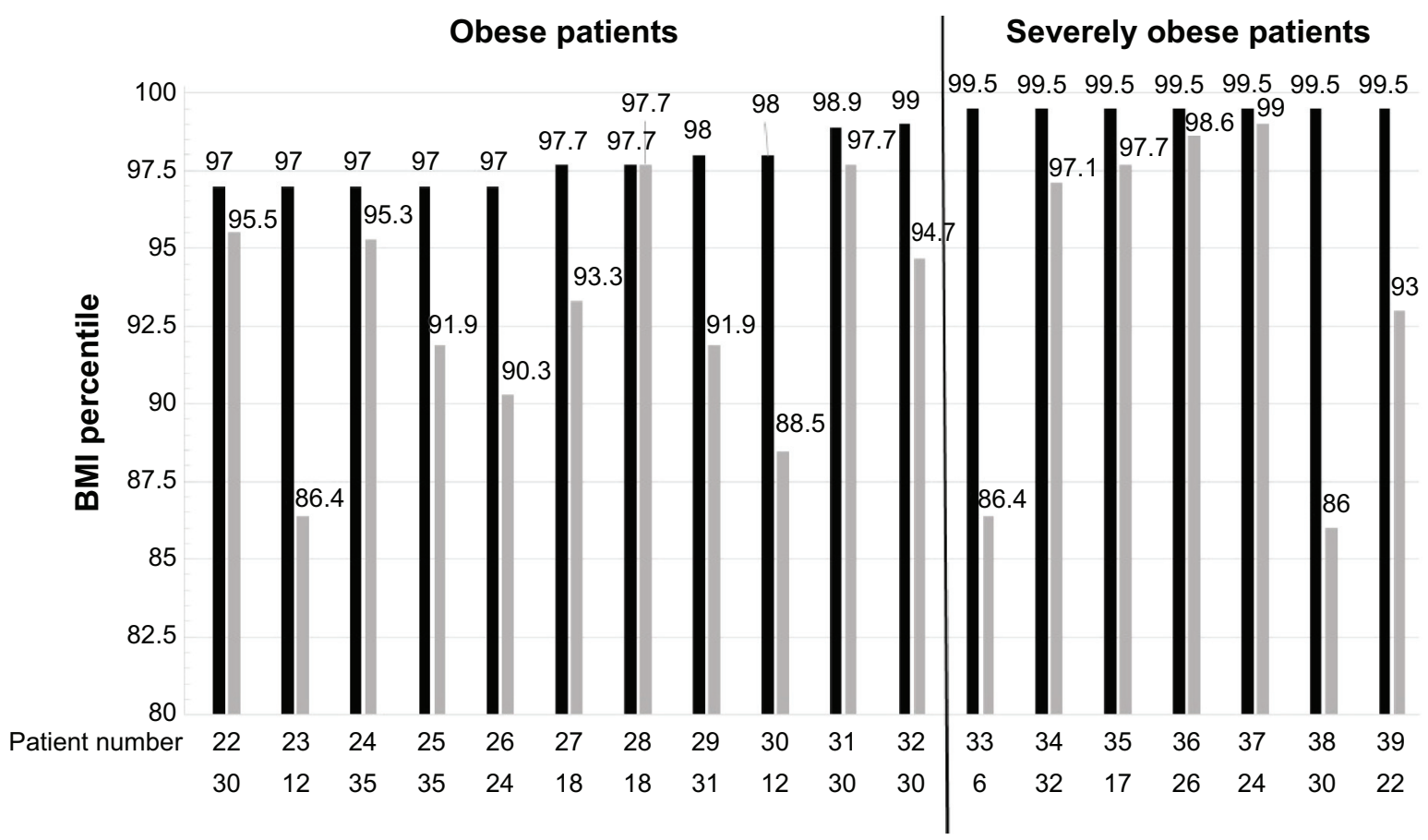

Figure 2 BMls of eleven obese (patient numbers 22-32) and seven severely obese (patient numbers 33-39) patients at the beginning of treatment and at the second measurement, 6-35 months later.

Notes: Black column: beginning of treatment; gray column: second measurement (6-35 months later). Months between first and second BMI evaluation are given in the second line.

Abbreviation: BMI, body mass index.

wear their appliances for less than a median of 3 hours per day during the first few months of treatment have an overall negative prognosis. Based on the monitoring data, patients can be encouraged to wear their devices, and individual circumstances can be taken into account for potential modification to management. This results in individual wear-time recommendations, which may increase acceptability and adherence from the patient perspective.

The printable wear-time graph allows the patient and orthodontist to easily visualize adherence over the treatment period and, consequently, the orthodontist can adapt the wear-time prescription to the personal circumstances and needs of the patient. Involving patients in treatment decisions and empowering them to take responsibility for their own treatment success is an important component of maintaining high adherence. Several obesity-related factors, for example, sleep-disordered breathing, ${ }^{40}$ obstructive sleep apnea syndrome, ${ }^{6}$ psychosocial problems, and poor self-esteem, ${ }^{41}$ might also be expected to influence the weartime adherence of obese patients. However, we found no evidence of obesity-related health problems negatively influencing wear time.

In earlier studies in which no wear-time documentation was used, a high percentage of patients treated with removable appliances lacked motivation. ${ }^{42,43}$ However, our longitudinal study using experimentally derived weartime documentation did not confirm this finding. All the known advantages of using integrated electronic wear-time documentation in removable devices compared to their permanent counterparts ${ }^{44}$ therefore fully apply, irrespective of the BMI of the patient. In this study, since wear-time adherence was only evaluated over a limited period during full active treatment, the relationship between adherence and treatment success could not be evaluated. In general, therapeutic success is not only dependent upon the appliance, but also on other factors, including the individual reaction of the dental-alveolar complex and an efficient treatment plan.

Many orthodontic patients hope to improve their appearance as well as correct malocclusion. ${ }^{45}$ It might therefore follow that as part of a general desire to improve, overweight/ obese patients also strive to lose weight over the course of orthodontic therapy. Regardless of this, it is expected that young orthodontic patients will lose weight over the course of orthodontic treatment due to their developmental and growth phase. The BMI of overweight/obese patients clearly fell in the majority of patients during therapy with removable appliances. It is possible that orthodontic therapy with removable 
appliances positively influenced a reduction in BMI; unfortunately, a relationship between the wear-time period, therapy time, and the BMI change could not be examined in this qualitative study. Due to the very heterogeneous nature of changes in BMI during the course of orthodontic treatment, it is likely that these changes were more significantly influenced by personal and individual conditions and less by the orthodontic treatment per se. For example, it is well known that in adolescents, development-related changes in growth, diet, sports activities, and increasing fashion consciousness can affect BMI. Given the numerous individual parameters that influence BMI during this critical developmental phase, only a limited interpretation of the effect of orthodontic treatment on the BMI of obese patients is possible based on these data.

Overweight or obese patients who reduce their BMI over the course of treatment do not require additional intervention. In patients with static or rising BMI, therapeutic measures for weight loss need to be considered, of which orthodontic intervention might be part of the overall plan to reduce weight. In these cases, modification of each individual's wear prescription might contribute to weight loss in the following ways. In contrast to permanent multibracket appliances, removable oral appliances reduce the size/space of the oral cavity and, for this reason, patients do not wear most removable appliances during meals. However, this reduced-space effect has been exploited as a patented removable dental approach for people with unhealthy BMIs, known as the DDS system. ${ }^{46}$ This tool is inserted into the upper palate and clipped onto the teeth, exactly the same as the upper jaw active orthodontic plate used in this study - the main difference being that the DDS system appliances have no orthodontic effect. A proof-of-concept study with the DDS appliance worn while eating showed that obese people wearing this appliance take smaller bites, slow their eating, and thus reduce food and calorific intake without affecting satiety and hunger ${ }^{47}$ the same effect might also be expected if orthodontic patients were to use their removable appliance, such as active plates or most unimaxillar functional appliances, during eating. Based on survey results, nearly $98 \%$ of children and adolescents from $2-18$ years of age regularly snack over the course of the day; ${ }^{20}$ wearing the appliance during the day could therefore also reduce snacking outside regular mealtimes. One approach might be to prescribe all-day wearing to overweight/obese orthodontic patients and stress that the appliance should always be worn during eating. Patients with unhealthy BMIs who intend to lose weight might also be motivated by orthodontic treatment with removable appliances if physicians outline the rationale for weight loss. The discomfort caused by the appliance during eating might subconsciously reduce the incentive to eat. The wear-time graphs obtained at each follow-up visit provide information about patients' adherence and indicate whether the appliance was worn during the day and during mealtimes. Based on this quantified information, the practitioner and the patient can collaborate to draw up an individualized, and thus more efficient, wear-time prescription. If needed, wear-time instructions can be adapted during therapy, according to changing circumstances.

Orthodontic therapy with removable appliances, therefore, opens up new opportunities for weight loss in obese patients. Whether, and how efficiently, the wearing of removable appliances during meals can help to reduce the BMIs of obese orthodontic patients needs to be quantified in a future study. Even orthodontic treatment with permanent multibracket appliances could be exploited for this purpose, since removable retention appliances are worn during the retention phase following every active treatment period. As recommended for general dentists by the American Academy of Pediatric Dentistry in its Policy on Dietary Recommendations for Infants, Children, and Adolescents, it would be desirable for orthodontists to calculate BMIs prior to or during treatment to help intervene and stem the tide of child obesity. ${ }^{20,48,49}$ In cases of young patients with BMI percentiles above 90, referral to pediatricians may be appropriate for further diagnosis and therapy. Wear times are monitored at check-up appointments, which take place approximately every 6-8 weeks over several years, and therefore consultation and encouragement during these sustained appointments by orthodontists may facilitate further weight loss in obese patients. Future studies need to be undertaken to examine to what extent overweight/obese patients take advantage of these actions and lose weight.

\section{Conclusion}

Wear times of patients with removable appliances are not negatively influenced by BMI, thus excluding BMI as a variable that needs to be considered when planning treatment with removable devices.

Adherence to removable devices is not BMI-dependent. Wearing the removable devices during mealtimes might represent a simple new strategy for weight reduction by hindering food intake, either physically or psychologically. In this way, obese patients might be treated using removable devices by combining orthodontic therapy and weight reduction strategies. 


\section{Acknowledgments}

We thank Professor Gregory Ludwig for helping to translate the manuscript, Aline Naumann for her statistical support, and all participants in the study. We acknowledge support by Deutsche Forschungsgemeinschaft (DFG) and Open Access Publishing Fund of Tuebingen University.

\section{Author contributions}

TCS designed the study, analyzed and interpreted the data, searched for literature, generated tables, and wrote the manuscript. BL designed the study and collected data. Both authors were involved in writing the paper and had final approval of the submitted and published version.

\section{Disclosure}

The authors report no conflicts of interest in this work.

\section{References}

1. WHO.int [homepage on the Internet]. Childhood overweight and obesity. World Health Organization; 2014. Available from: http://www. who.int/dietphysicalactivity/childhood/en/. Accessed June 19, 2014.

2. Abrams P, Levitt Katz LE. Metabolic effects of obesity causing disease in childhood. Curr Opin Endocrinol Diabetes Obes. 2011;18(1):23-27.

3. Friedlander SL, Larkin EK, Rosen CL, Palermo TM, Redline S. Decreased quality of life associated with obesity in school-aged children. Arch Pediatr Adolesc Med. 2003;157(12):1206-1211.

4. Kopelman PG. Obesity as a medical problem. Nature. 2000;404(6778): 635-643.

5. Lobstein T, Baur L, Uauy R; IASO International Obesity TaskForce. Obesity in children and young people: a crisis in public health. Obes Rev. 2004;5 Suppl 1:4-104.

6. Marcus CL, Curtis S, Koerner CB, Joffe A, Serwint JR, Loughlin GM. Evaluation of pulmonary function and polysomnography in obese children and adolescents. Pediatr Pulmonol. 1996;21(3):176-183.

7. Must A, Strauss RS. Risks and consequences of childhood and adolescent obesity. Int J Obes Relat Metab Disord. 1999;23 Suppl 2: S2-S11.

8. Weiss R, Dziura J, Burgert TS, et al. Obesity and the metabolic syndrome in children and adolescents. $N$ Engl J Med. 2004;350(23):2362-2374.

9. Friedemann C, Heneghan C, Mahtani K, Thompson M, Perera R, Ward AM. Cardiovascular disease risk in healthy children and its association with body mass index: systematic review and meta-analysis. $B M J$. 2012; 345:e4759.

10. Busetto L, Sergi G. Visceral fat and respiratory complications. Diabetes Obes Metab. 2005;7(4):301-306.

11. Esposito M, Antinolfi L, Gallai B, et al. Executive dysfunction in children affected by obstructive sleep apnea syndrome: an observational study. Neuropsychiatr Dis Treat. 2013;9:1087-1094.

12. Carotenuto M, Esposito M, Parisi L, et al. Depressive symptoms and childhood sleep apnea syndrome. Neuropsychiatr Dis Treat. 2012;8: 369-373.

13. Carpenter KM, Hasin DS, Allison DB, Faith MS. Relationships between obesity and DSM-IV major depressive disorder, suicide ideation, and suicide attempts: results from a general population study. Am J Public Health. 2000;90(2):251-257.

14. Strauss RS, Pollack HA. Social marginalization of overweight children. Arch Pediatr Adolesc Med. 2003;157(8):746-752.

15. Alm A, Fåhraeus C, Wendt LK, Koch G, Andersson-Gäre B, Birkhed D. Body adiposity status in teenagers and snacking habits in early childhood in relation to approximal caries at 15 years of age. Int $J$ Paediatr Dent. 2008;18(3):189-196.
16. Costacurta M, Di Renzo L, Bianchi A, Fabiocchi F, De Lorenzo A, Docimo R. Obesity and dental caries in paediatric patients. A crosssectional study. Eur J Paediatr Dent. 2011;12(2):112-116.

17. Fadel HT, Pliaki A, Gronowitz E, et al. Clinical and biological indicators of dental caries and periodontal disease in adolescents with or without obesity. Clin Oral Investig. 2014;18(2):359-368.

18. Honne T, Pentapati K, Kumar N, Acharya S. Relationship between obesity/overweight status, sugar consumption and dental caries among adolescents in South India. Int J Dent Hyg. 2012;10(4):240-244.

19. Hooley M, Skouteris H, Millar L. The relationship between childhood weight, dental caries and eating practices in children aged 4-8 years in Australia, 2004-2008. Pediatr Obes. 2012;7(6):461-470.

20. Spiegel KA, Palmer CA. Childhood dental caries and childhood obesity. Different problems with overlapping causes. Am J Dent. 2012; 25(1):59-64.

21. Kantovitz KR, Pascon FM, Rontani RM, Gavião MB. Obesity and dental caries - A systematic review. Oral Health Prev Dent. 2006;4(2): 137-144.

22. Khosravi R, Tran SD, Lambert M, et al. Adiposity and gingival crevicular fluid tumour necrosis factor-alpha levels in children. J Clin Periodontol. 2009;36(4):301-307.

23. Modéer T, Blomberg C, Wondimu B, Lindberg TY, Marcus C. Association between obesity and periodontal risk indicators in adolescents. Int J Pediatr Obes. 2011;6(2-2):e264-e270.

24. Giuca MR, Pasini M, Tecco S, Marchetti E, Giannotti L, Marzo G. Skeletal maturation in obese patients. Am J Orthod Dentofacial Orthop. 2012;142(6):774-779.

25. Neeley WW, Gonzales DA. Obesity in adolescence: implications in orthodontic treatment. Am J Orthod Dentofacial Orthop. 2007;131(5): 581-588.

26. von Bremen J, Wagner J, Ruf S. Correlation between body mass index and orthodontic treatment outcome. Angle Orthod. 2013;83(3): 371-375.

27. Kromeyer-Hauschild K, Wabitsch M, Kunze D, et al. Percentile of body mass index in children and adolescents evaluated from different regional German studies. Monatsschr Kinderheilkd. 2001;149:807-817.

28. Cole TJ, Bellizzi MC, Flegal KM, Dietz WH. Establishing a standard definition for child overweight and obesity worldwide: international survey. BMJ. 2000;320(7244):1240-1243.

29. Cole TJ. The LMS method for constructing normalized growth standards. Eur J Clin Nutr. 1990;44(1):45-60.

30. Schott TC. Einbau eines Mikrosensors in herausnehmbare kieferorthopädische Geräte. Quintessenz Zahntech. 2011;37:898-904.

31. Schott TC, Göz G. Wearing times of orthodontic devices as measured by the TheraMon ${ }^{\circledR}$ microsensor. J Orofac Orthop. 2011;72(2):103-110.

32. Schott TC, Schlipf C, Glasl B, Schwarzer CL, Weber J, Ludwig B. Quantification of patient compliance with Hawley retainers and removable functional appliances during the retention phase. Am J Orthod Dentofacial Orthop. 2013;144(4):533-540.

33. Schäfer K, Ludwig B, Meyer-Gutknecht H, Schott TC. Quantifying patient adherence during active orthodontic treatment with removable appliances using microelectronic wear-time documentation. Eur J Orthod. 2014

34. Tsomos G, Ludwig B, Grossen J, Pazera P, Gkantidis N. Objective assessment of patient compliance with removable orthodontic appliances: a cross-sectional cohort study. Angle Orthod. 2014;84(1):56-61.

35. Kawala B, Antoszewska J, Sarul M, Kozanecka A. Application of microsensors to measure real wear time of removable orthodontic appliances. Journal of Stomatology. 2013;66:321-330.

36. Pauls A, Nienkemper M, Panayotidis A, Wilmes B, Drescher D. Effects of wear time recording on the patient's compliance. Angle Orthod. 2013; 83(6): 1002-1008.

37. Proffit WR, Fields HW Jr, Sarver DM. Contemporary Orthodontics. 4th ed. St Louis, MO: Mosby Elsevier; 2007.

38. Sahm G, Bartsch A, Witt E. Micro-electronic monitoring of functional appliance wear. Eur J Orthod. 1990;12(3):297-301. 
39. Schott TC, Ludwig B. Microelectronic wear-time documentation of removable orthodontic devices detects heterogeneous wear behavior and individualizes treatment planning. Am J Orthod Dentofacial Orthop. 2014;146(2):155-160.

40. Carotenuto M, Bruni O, Santoro N, Del Giudice EM, Perrone L, Pascotto A. Waist circumference predicts the occurrence of sleep-disordered breathing in obese children and adolescents: a questionnaire-based study. Sleep Med. 2006;7(4):357-361.

41. Witherspoon D, Latta L, Wang Y, Black MM. Do depression, selfesteem, body-esteem, and eating attitudes vary by BMI among African American adolescents? J Pediatr Psychol. 2013;38(10):1112-1120.

42. Barton S, Cook PA. Predicting functional appliance treatment outcome in Class II malocclusions - a review. Am J Orthod Dentofacial Orthop. 1997;112(3):282-286.

43. Ghafari J, Shofer FS, Jacobsson-Hunt U, Markowitz DL, Laster LL. Headgear versus function regulator in the early treatment of Class II, division 1 malocclusion: a randomized clinical trial. Am J Orthod Dentofacial Orthop. 1998;113(1):51-61.

44. Stolze A, Goldbecher H, Stubbe C. Treatment with removable appliances. An account of experiences after 40 years working as an orthodontist. Kieferorthop. 2010;24:195-213.
45. Perillo L, Esposito M, Caprioglio A, Attanasio S, Santini AC, Carotenuto M. Orthodontic treatment need for adolescents in the Campania region: the malocclusion impact on self-concept. Patient Prefer Adherence. 2014;8:353-359.

46. Walden HM, Martin CK, Ortego LE, Ryan DH, Williamson DA. A new dental approach for reducing food intake. Obes Res. 2004;12(11): 1773-1780.

47. Ello-Martin JA, Ledikwe JH, Rolls BJ. The influence of food portion size and energy density on energy intake: implications for weight management. Am J Clin Nutr. 2005;82(1 Suppl):236S-241S.

48. American Academy of Pediatric Dentistry Clinical Affairs Committee; American Academy of Pediatric Dentistry Council on Clinical Affairs. Policy on dietary recommendations for infants, children, and adolescents. Pediatr Dent. 2005-2006;27(7 Supp1):36-37.

49. Tseng R, Vann WF Jr, Perrin EM. Addressing childhood overweight and obesity in the dental office: rationale and practical guidelines. Pediatr Dent. 2010;32(5):417-423.
Patient Preference and Adherence

\section{Publish your work in this journal}

Patient Preference and Adherence is an international, peer-reviewed, open access journal that focuses on the growing importance of patient preference and adherence throughout the therapeutic continuum. Patient satisfaction, acceptability, quality of life, compliance, persistence and their role in developing new therapeutic modalities and compounds to optimize

\section{Dovepress}

clinical outcomes for existing disease states are major areas of interest for the journal. This journal has been accepted for indexing on PubMed Central. The manuscript management system is completely online and includes a very quick and fair peer-review system, which is all easy to use. Visit http://www. dovepress.com/testimonials.php to read real quotes from published authors. 